DOI: 10.30680/ECO0131-7652-2019-11-156-171

\title{
Реформа железнодорожного транспорта России: «последняя миля»1
}

С.А. БЫКАДОРОВ, доктор экономических наук, Сибирский государственный университет путей сообщения. E-mail: byser@ngs.ru

Е.Б. КИБАЛОВ, доктор экономических наук, Институт экономики и организации промышленного производства СО РАН, Новосибирск. E-mail: kibalovE@mail.ru

Аннотация. В статье критически анализируется Долгосрочная программа развития ОАО «Российские железные дороги» до 2025 г. и рассматриваются возможные варианты совершенствования модели управления обществом в условиях санкций и военных угроз со стороны коллективного Запада. По мнению авторов, начатая 25 лет назад реформа железнодорожного транспорта до своего обещанного результата не дошла и (если рассматривать Программу 2025 как ее «последнюю милю») повернула вспять: скорость перевозки грузов и пассажиров недопустимо мала, тарифы непрерывно растут. На примере восточного железнодорожного полигона страны обсуждаются проблемы оценки сравнительной общественной эффективности железнодорожных проектов двойного назначения (социально-экономического и военно-стратегического): Трансполярной, ЛенскоКамчатской магистралей и железной дороги материк-Сахалин.

Ключевые слова: долгосрочная программа; сценарии; санкции; фактор неопределенности; железнодорожные проекты двойного назначения; реформа; РЖД; Европейская Россия; Азиатская Россия; Севморпуть

Предварительные замечания. В наших прежних публикациях [Кибалов, Кин, 2017; Быкадоров, Кибалов, 2018] Структурная реформа железнодорожного транспорта², реализуемая в течение последних 25 лет (далее - Реформа), рассматривалась как неудавшийся институциональный проект федеральной значимости. В работе 2017 г. реформа анализировалась с помощью

\footnotetext{
${ }^{1}$ Исследование выполнено при финансовой поддержке РФФИ в рамках научного проекта № 19-010-00161А.

${ }^{2}$ Напомним, что основной идеей структурной реформы было расщепление прежнего МПС СССР (МПС России) на две структурные единицы, первая из которых - государственный регулятор-осуществляла стратегическое регулирование железнодорожной деятельности в интересах общества, вторая - ОАО «РЖД»осуществляла хозяйственное управление отраслевыми активами; отдельные виды деятельности приватизированы (грузовой парк в основном был передан частным компаниям-операторам). Целью соответствующей государственной Программы было включение механизма конкуренции на рынке железнодорожных перевозок и, как следствие, повышение эффективности отрасли.
} 
экспертных опросов ${ }^{3}$, оценивались варианты ее дальнейшего институционального проектирования. Тогда все участвовавшие в исследовании эксперты сошлись во мнении, что в ситуации неопределенности оптимальным вариантом из всех возможных было бы сохранение «нынешней модели управления дорогами общего пользования и наложение запрета на дальнейшее экспериментирование» ${ }^{4}$. Этот вывод оказался верным, что подтверждают как заявления пореформенных руководителей ОАО «РЖД» (далее РЖД), так и текст последней принятой «Долгосрочной программы развития ОАО "Российские железные дороги" до 2025 г.» ${ }^{5}$ (далее Программа 2025).

Изучение и тех, и других порождает новые вопросы относительно дальнейшей судьбы РЖД: 1) как долго продлится пауза в эксперименте? 2) не завершится ли многолетняя Реформа реинкарнацией Министерства путей сообщения (МПС) РФ? Попытка ответить на эти вопросы и составляет содержание настоящей статьи.

\section{Критический анализ Программы 2025}

Начнем с анализа задач, которые государство-регулятор (и единственный акционер РЖД) ставит перед естественным монополистом в упомянутой Программе 2025, определяющей стратегию его развития на среднесрочную перспективу.

В данном документе первой по порядку формулируется задача получения финансовых ресурсов, необходимых для исполнения установок государства, и в этом видится путь повышения финансовоэкономической эффективности отрасли. Однако дальнейшее пояснение в тексте Программы 2025, утверждающее, что она основана на действующих нормативно-правовых актах с сохранением статускво на рынке грузовых и пассажирских железнодорожных перевозок до 2025 г., фактически ставит крест на реализации и первой, и всех остальных ее целей и задач. Потому что это означает, что сохраняется

\footnotetext{
${ }^{3}$ Коллектив экспертов состоял из авторитетных специалистов в области экономики железнодорожного транспорта, макроэкономики и смежных проблем и включал представителей Сибирского государственного университета путей сообщения и ученых ИЭОПП СО РАН.

${ }^{4}$ Под нынешней моделью управления в экспертизе понималось ее (модели) состояние на 2016 г., а объектом управления для РЖД были только железные дороги общего пользования.

${ }^{5}$ Утверждена распоряжением Правительства РФ от 19 марта 2019 г. № 466-р, текст доступен на сайте правительства РФ. URL: http://static.government.ru/media/files/zcAM xApAgyO7PnJ42aXtXAga2RXSVoKu.pdf
} 
многолетний механизм недофинансирования государством деятельности РЖД. И в этих условиях результаты реализации Программы, скорее всего, будут негативными, точно так же, как этот случилось с Реформой [Кибалов, Кин, 2017].

Если же проанализировать систему ограничений, фиксируемых в форме законных и подзаконных актов, тщательно выписанных в Программе 2025 и образующих ее институциональную среду, становится очевидным следующее. Ограничения образуют столь узкий коридор для РЖД, по сравнению с которым свобода в выборе эффективных решений, существовавшая в МПС СССР, а затем в МПС РФ, кажется образцом научно обоснованного подхода, опирающегося на «инициативу снизу».

В свете сказанного ответ на первый вопрос, поставленный в начале статьи, в общем виде таков: пауза в эксперименте по реформированию модели управления ОАО «РЖД» должна, с нашей точки зрения, продлиться до того момента, когда отсутствие свободы выбора эффективных решений «снизу» будет ликвидировано, точнее, сбалансировано с регулячиями «сверху». До тех пор, пока этого не произойдет, РЖД будет находиться в институциональной ловушке [Кибалов, Кин, 2017] и перевозить грузы со средней скоростью 16,1 км/ч 7 , которая не слишком отличается от велосипедной, а пассажиров - со скоростью 57 км/ч .

Обратимся далее к разделу V Программы 2025, где речь идет о рисках, влияющих на ее результирующие показатели. На наш взгляд, качество его подготовки весьма спорно. Во-первых, все так называемые критические риски перекладываются на государство, во-вторых, авторы документа не учитывают принципиальных различий между риском (вероятностной неопределенностью) и неопределенностью радикальной.

Поясним последний тезис подробнее. В тексте Программы 2025 традиционно предусматриваются два сценария развития экономики страны: «базовый» и «оптимистический», в рамках которых в логике или-или предположительно будут осуществляться программные мероприятия.

${ }^{6}$ Cм. URL: https://npktrans.ru/Doc.aspx?docId=14564\&CatalogId=653 (дата обращения: 26. 09. 2019).

${ }^{7}$ URL: http://www.ipem.ru/files/files/research/20190405_rail_2025_report.pdf

${ }^{8}$ URL: https://www.mintrans.ru/press-center/branch-news/595 (дата обращения: 28.06. 2019). 
Совершенно непонятно, почему (в нарушение всех канонов системного анализа) в документе отсутствует сценарий пессимистический, актуализация которого, по сути, и привела к провалу Реформы, предшественнице нынешней Программы 2025 и на чем основан подобный «базовый оптимизм» в ситуации вялотекущего финансового кризиса, экономических санкций и хрупкости действующей сверхцентрализованной модели управления РЖД [Кибалов и др. 2015].

Оба сценария Программы 2025 - базовый и оптимистический, как подчеркивается в тексте, основаны на базовом сиенарии развития экономики страны, разработанном Минэкономразвития. Но если база одинакова, чем две ее «производных» отличаются друг от друга? Если лишь второстепенными подробностями, то это противоречит самой сути сценарного подхода, в контексте которого для адекватного учета фактора радикальной неопределенности сценарии должны быть контрастно различныли и представлять разную степень детализации на разных уровнях экономической системы. То есть, по мнению авторов, исключение пессимистического сценария из состава альтернатив развития внешней среды Программы 2025 методологически ошибочно, так же как и принятие такого подхода правительством РФ, которое просто обязано учитывать возможность реализации самых плохих сценариев, именуемых на Западе «черными лебедями» [Талеб, 2015].

Описания рисков в обоих сценариях Программы 2025 представляются не вполне логичными. Если сценарий оптимистический, то есть «внешняя среда», по определению, должна способствовать достижению оптимальных показателей РЖД в долгосрочной перспективе, то этот оптимум по всем результирующим показателям должен быть однозначно зафиксирован в тексте документа. Однако этого не происходит. В первой же строке табличного описания сценариев (Приложение № 24 к Программе 2025) приводится показатель «Снижение среднего темпа роста грузооборота за период 2019-2025 гг.», и этот показатель дифференцирован по вариантам.

Как известно, грузооборот в своей основной части зависит от состояния и темпов развития экономики страны, и на этот показатель «подвешена» вся экономика РЖД. Тем не менее естественный монополист, пользуясь в собственных интересах (с позволения правительства) возможностью манипулировать 
грузовыми тарифами, доступом «к рельсам» независимых перевозчиков и инструментами технического регулирования, тоже влияет на снижение грузооборота и должен нести свою долю ответственности за последствия этих действий. Поэтому, на наш взгляд, в Программе 2025 следовало бы указать прогнозируемую долю «вклада» РЖД в снижение грузооборота, что позволило бы конкретизировать меры по снижению волатильности этого важнейшего при управлении финансовыми рисками показателя.

Из всего сказанного вытекает второй вопрос, сформулированный в начале статьи: не ведет ли Программа 2025 к реинкарнации МПС РФ. В отношении четвертьвековой Реформы железнодорожного транспорта Программа, рассчитанная на семь лет, является своего рода «последней милей». И такой исход Реформы беспокоит экспертное сообщество (см., например [Лебедев, 2019]).

\section{Что такое «последняя миля»}

В научном обороте этот термин означает последний этап в процессе продуцирования экономического блага-его продажу или передачу непосредственно потребителю. Применительно к Реформе благом является механизм управления общественным железнодорожным транспортом страны, который должен вносить позитивный вклад в устойчивое развитие экономики и общества в неустойчивой (или, как теперь модно говорить, - турбулентно развивающейся) внешней среде.

Подчеркнем, что проблема «последней мили» по-разному преломляется в разных сферах деятельности. Так, Ю.П. Воронов в одной из своих работ [Воронов, 2019] рассматривает специфику действий на «последней миле» в электро- и теплоэнергетике, на транспорте, в логистике, в Интернете, в образовании. Автор приходит к выводу, что услуга, предоставляемая на «последней миле», не может измеряться в тех же показателях, что и услуга магистральных сетей. Например, в электроэнергетике конечные потребители могут сами генерировать энергию (посредством ветряных и солнечных электростанций) и отдавать ее в общую сеть. При этом возникает феномен «отрицательного тарифа».

Не споря с этими утверждениями, отметим, что на транспорте имеется своя специфика «последней мили». И, разумеется, возникают специфические проблемы ее преодоления. 
При организации цепи поставок важное значение имеет ликвидация так называемых «узких мест», т.е. тех звеньев логистической цепи, которые ограничивают или тормозят процесс создания стоимости продукта всей цепи. В классической схеме сетевой структуры цепи поставок [Иванов, 2009. С. 58] одним из таких узких мест является процесс передачи товара ближайшему контрагенту «справа» от фокусной компании. Собственно, это и есть «последняя миля» транспортировки. На железной дороге процесс ее преодоления зависит от взаимоотношений монополиста РЖД (и его дочерних структур) с пользователями транспортных услуг, т.е. конкурентной средой. Как свидетельствует широкая арбитражная практика, РЖД под различными предлогами старается ограничить доступ к государственной инфраструктуре компаниям, которые хотели бы вывозить грузовые контейнеры с площадок своим транспортом9

Кроме того, «узкими местами» часто становятся «стыки» между магистральным и промышленным железнодорожным транспортом. Частные компании, обладающие специализированным составом для перевозки промышленных грузов, находятся в логистической цепи между промышленными предприятиями тех или иных отраслей (горнодобывающей, металлургической и др.) и магистральными железными дорогами. При использовании подвижного состава и инфраструктуры разных собственников и разделении затрат между ними нередко возникают проблемы (кстати, по характеру этих проблем «последнюю милю» можно отождествлять с «первой милей», т.е. первым этапом в цепи поставок «промышленные предприятия-магистральные железные дороги»).

Другой пласт специфических проблем «последней мили» на транспорте связан с различиями в толкованиях показателя «транспортной продукции», который нередко смешивают с понятием «транспортная работа», что в корне неверно ${ }^{10}$.

На рисунке показаны два варианта доставки 1 т однородной продукции из пункта А в пункт В разными путями: кратчайшим $\left(l_{1}=1000 \kappa м\right)$ и кружным $\left(l_{2}=1500 \kappa M\right)$. Продукция в обоих

\footnotetext{
${ }^{9}$ Полное представление о проблемной ситуации желающие могут получить, изучив материалы сети Интернет по ключевым словам «арбитражная практика РЖД».

10 Экономика железнодорожного транспорта: учебник / Под ред. Н. П. Терёшиной, Л. П. Левицкой, Л. В. Шкуриной. М.: ФГБОУ «Учебно-методический центр по образованию на железнодорожном транспорте», 2012. С. 110.
} 
вариантах одинакова: из А в В доставлена 1 т груза. Но в варианте I затраченная на единицу продукции транспортная работа (грузооборот) составляет 1000 т·км, а при варианте II - 1500 т·км. На этом примере мы видим, что продукция - результат транспортного производства, а работа - его затраты. Первый показатель определяет доход транспорта, а второй - расход.

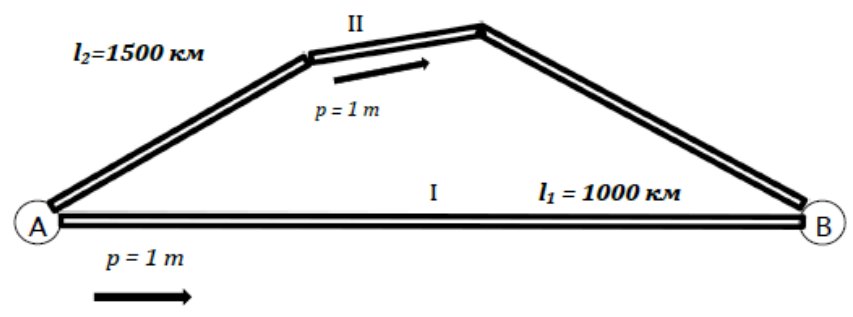

Продукция и работа транспорта

Отсюда ясно, что искать резервы увеличения прибыли, повышения эффективности транспортного производства следует в сокращении транспортной работы на единицу продукции.

К сожалению, современное тарифное регулирование на железнодорожном транспорте этому не способствует, будучи подвержено воздействию различных и часто противоречивых факторов.

С одной стороны, тарифная составляющая транспортного бизнеса в рыночной экономике формируется на основе спроса и предложения, с другой - в естественно-монополистических секторах, к которым относится и железнодорожная отрасль, должен действовать принцип безубыточности: доходная ставка должна превышать себестоимость перевозок на величину рентабельности.

Кроме того, наряду с дифференциацией грузов на три класса, которая применяется при проектировании тарифов для перевозки массовых грузов, необходимо учитывать еще и тарифно-ценовую эластичность спроса на некоторые из них в пунктах доставки («пунктах распыления»).

Проектирование тарифов на пассажирские перевозки - это отдельный вопрос, так как они почти повсеместно в РФ дотируются из бюджета исходя из соображений социального или политического характера. Тем не менее ценовая эластичность спроса и на пассажирских перевозках остается актуальной. Например, считается, что спрос на пригородные железнодорожные перевозки эластичен, а на дальние - нет. Именно поэтому в разных субъектах Федерации 
периодически возникают проблемы с отменой убыточных пригородных поездов или остановок поездов дальнего следования.

Необходимо отметить, что «последняя миля» на железнодорожном транспорте имеет сильные региональные различия. Восток страны, где в отсутствие развитой ж/д сети естественный монополист «Транссиб» довозит грузы и пассажиров по назначенным «сверху» тарифам только до станций - это нерыночное пространство, в котором «последняя миля» представляет собой сотни километров по бездорожью до конечных носителей платежеспособного спроса.

В европейской части страны, где имеется плотная даже по западным меркам железнодорожная сеть, функционирует конкурентный транспортный рынок; грузоотправители и грузополучатели, а также пассажиры имеют возможность выбрать наиболее предпочтительный маршрут (вплоть до высокоскоростного). Механизм конкуренции делает тарифную политику РЖД более социально справедливой, а «последнюю милю» на порядок короче, чем в восточных регионах РФ.

К сказанному необходимо добавить, что у разных акторов рынка (в том числе железнодорожного) понимание «последней мили» различается, как различаются их цели и задачи. Государство обязано заботиться о гармоничном развитии всех территорий, поддерживать социальную справедливость, гарантируя каждому клиенту возможность получения равного эффекта от «недискриминированного доступа» операторов и экспедиторов «к рельсам». Цель же РЖД (продекларированная в Программе 2025) - получение средств ${ }^{11}$ на развитие своей инфраструктуры (здания, сооружения, подвижной состав и т.п.). По сути, речь идет о максимизации корпоративной выгоды. Таким образом, РЖД, будучи государственной корпорацией, по необходимости должна решать двуединую задачу: как государственный агент быть социально эффективной, как рыночный - эффективной коммерчески.

\section{Вернемся к Программе 2025}

Приведем наши предложения относительно того, каким образом следовало бы пройти «последнюю милю» в процессе

${ }^{11}$ По большей части речь идет о бюджетных средствах, о чем свидетельствует проведенный авторами анализ таблиц, прилагаемых к Программе. 
затянувшегося реформирования РЖД и адекватно отреагировать на вызовы внешней среды, системная неопределенность развития которой возрастает. Эти предложения фокусируются на усилении роли железных дорог Сибири и Дальнего Востока как инструмента двойного назначения: а) обеспечивающего устойчивое социально-экономическое развитие восточных территорий страны и б) системообразующего элемента национальной безопасности России на ее восточных рубежах. Так называемый восточный полигон РЖД состоит из широтных Транссибирской и Байкало-Амурской магистралей и связанной с ними системы широтных и меридиональных капиллярных линий.

В рамках социально-экономического аспекта особенностью транспортной системы Сибирского, Дальневосточного и большей части Уральского федеральных округов является отсутствие иных, кроме железной дороги, транспортных возможностей для эффективной доставки значительных объемов массовых грузов. В отличие от европейской части страны, здесь нет разветвленной транспортной сети. Каким образом государство-регулятор должно реагировать на эту ситуацию вопиющего территориального неравенства? Есть два типа регуляций в отношении «недоразвитости» железных дорог: поведенческие и структурные. Рассмотрим сначала первые из них.

По нашему мнению, на железнодорожных полигонах европейской и азиатской частей России было бы правильно и логично применять разные тарифные системы (по крайней мере, по грузовым перевозкам). В европейской части страны, где есть разветвленная транспортная сеть и существует реальная конкуренция, можно применять конкурентные рыночные тарифы, а в азиатской, где все это отсутствует, - регулировать тарифы «сверху». Централизация регулирования спроса и предложения транспортных услуг на Восточном полигоне во многих случаях даст возможность увеличить загрузку транспорта, и за счет повышения выручки (даже при неизменных удельных тарифах) получить средства на реконструкцию транспортной инфраструктуры и социальные цели работников отрасли.

Примыкает к вышеописанному и следующее предложение. На отечественном железнодорожном транспорте исторически существует такое понятие, как «полоса отвода»- земельные участки, прилегающие к железнодорожным объектам (пути, 
станции, водоотводные системы, линии связи, энергетическая инфраструктура, защитные лесонасаждения и т.д.) или предназначенные для их размещения ${ }^{12}$. Если эти участки будут переданы из федеральной в собственность субъекта Федерации, местные органы смогут получать так называемую «транспортную ренту», т.е. часть тарифа от грузов, проходящих через территорию. Из исторических аналогов «транспортной ренты» можно вспомнить известный «челябинский тарифный перелом» ${ }^{13}$. По нашему мнению, в случае принятия подобных предложений, «последняя миля» на железных дорогах востока России (часто - растянутая на десятки и сотни километров) будет приносить больший эффект для национальной и региональной экономики.

Еще одна коллизия, которая требует рассмотрения применительно к повышению социально-экономической эффективности РЖД, связана с межотраслевым регулированием. Известно, что экспортно ориентированная отечественная экономика доставляет груз до морских портов довольно дешевым и низкорентабельным железнодорожным транспортом, а для отправки его за рубеж использует гораздо более дорогой и доходный морской. На наш взгляд, было бы справедливо, если бы «последняя миля» морского транспорта делилась своими доходами с внутренними перевозчиками, которые «подвозят» для него массовые грузы.

Структурные регуляции государства в отношении Восточного полигона РЖД дополняют контурно описанные выше регуляции поведенческие ${ }^{14}$, закрепляя их по месту реализации (т.е. на железных дорогах Сибири и Дальнего Востока). В настоящее время

\footnotetext{
${ }^{12}$ Приказ Минтранса РФ от 6 августа 2008 г. № 126 «Об утверждении Норм отвода земельных участков, необходимых для формирования полосы отвода железных дорог, а также норм расчета охранных зон железных дорог».

${ }^{13}$ Специальные правила тарифообразования, действовавшие в 1896-1913 годах при провозе зерна и муки с из восточных регионов в западные через станцию Челябинск (на тот момент через нее проходил единственный железнодорожный маршрут, связывающий Сибирь и Урал с европейской частью России). По общему правилу, на российских железных дорогах действовал понижательный грузовой тариф: чем дальше расстояние, тем ниже стоимость пудо-версты. В Челябинске тариф на сибирские зерно и муку, отправляемые на запад, исчислялся заново, а все накопленные «скидки» обнулялись. Такой порядок начисления тарифа, пролоббированный зернопроизводителями центральных и южных губерний, придавал ему характер внутренней таможенной пошлины.

14 Эта идея в принципе не нова и применительно к Структурной реформе железнодорожного транспорта России (после тщательного анализа международного опыта) была высказана Р. Питтманом в его работе [Pittman 2004], но, к сожалению, отечественными реформаторами услышана не была.
} 
РЖД осуществляет свою деятельность экстерриториально не только на территории РФ, но и в международном сообщении ${ }^{15}$.

Прежние МПС СССР и МПС РФ тоже действовали экстерриториально, но модель управления этими министерствами была территориально-функциональной, т.е. сочетала принципы хозяйственной самостоятельности 17 региональных железных дорог и жестко централизованной планово-командной координации со стороны министерств по ключевым параметрам деятельности отрасли.

Структурная реформа железнодорожного транспорта была попыткой повысить его общественную эффективность посредством трансплантации в эту, по сути, имперскую модель управления, складывавшуюся десятилетиями, элементов рыночной экономики. Провал этой попытки был предсказан теоретически (см., например [Полтерович, 1999]), подтвержден на практике и официально признан в 2015 г. [Кибалов, Кин, 2017].

Что же мы имеем «в сухом остатке»? Модель управления РЖД по видам деятельности, которая пришла на смену территориальнофункциональной модели? Но какова ее эффективность по сравнению с предшественницей? Почему механизм конкуренции так и не заработал, а монополизм РЖД лишь укрепился? Как холдингу удается сочетать идеологии отдельных бизнес-единиц и единого хозяйствующего субъекта? И вообще, правомерно ли РЖД был «назначен» естественным монополистом, а не классифицирован, скажем, как легальный картель с государством? На все эти вопросы за четыре года после официальной кончины Реформы ни один из ее инициаторов так и не ответил. В то же время своего рода коллективным ответом является текст Программы 2025, где по справедливому замечанию известного экономиста, члена Экспертного совета по железнодорожному транспорту при ФАС России Ф.И. Хусаинова: «Все то, от чего планировалось уйти в начале реформ, провозглашено теперь целью, которая зацементирована в Долгосрочной программе развития» ${ }^{16}$.

Мы полагаем, что такого рода финал не должен стать «последней милей»- концом истории реформирования системы управления железнодорожным транспортом России. Для того, чтобы это не произошло, поведенческие регуляции государства следует дополнить структурными, и только такой системный

${ }^{15}$ URL: http://www.rzd.ru/static/public/ru? STRUCTURE_ID=660 (дата обращения: 28.06. 2019).

${ }^{16}$ URL: https://f-husainov.livejournal.com/646550.html (дата обращения: 28.06. 2019). 
подход избавит реформу от ведомственной зашоренности и сориентирует на общественно полезный результат.

Конкретные предложения состоят в том, чтобы - в целях снятия противоречия между общественными и коммерческими целями РЖД - расщепить эту уникальную структуру на две части: РЖД-Европа и РЖД-Азия. Полигоном деятельности первой из них определить европейскую часть России, где имеется плотная сеть железных дорог и конкуренция со стороны иных видов транспорта. Если естественность монополизма РЖД-Европа будет доказана вызывающими доверие методами, то предлагаемое решение будет экономически оправданным; если нет, необходимо создать не менее двух частных железнодорожных компаний, конкурирующих на транспортном рынке в борьбе за удовлетворение платежеспособного спроса ${ }^{17}$. Будут ли они при этом владеть или только пользоваться рельсами и тягой - вопрос серьезный, но не стратегический. Важно, что они будут сняты с государственного кошта и переведены на рыночный «корм», что и станет их общественно эффективным вкладом в развитие страны ${ }^{18}$.

В отношении РЖД-Азия должны быть приняты другие меры. Этой компании необходимо придать статус казенного предприятия, нацеленного на решение стратегических задач государства на гигантских слабозаселенных и «транспортно недостаточных» территориях восточной части страны. Будет ли она решать эти задачи собственными силами, на основе механизма государственно-частного партнерства или с привлечением иностранных партнеров - вопросы важные, но опять же не стратегические. Самое главное здесь - наличие длинной контролирующей и инвестирующей «руки Центра», направляющего деятельность РЖД-Азия на решение стратегической проблемы диверсификации внешних связей страны путем развития торгово-экономических отношений со странами АТР. Опорной структурой для РЖД-Азия естественным образом является Транссиб с его ответвлениями на Китай и выходом на Транскорейскую железнодорожную магистраль.

\footnotetext{
${ }^{17}$ Вариант горизонтального разделения сети железных дорог в Европейской России на два автономных блока с передачей их в концессию двум конкурирующим вертикально интегрированным железнодорожным компаниям выдвигался еще на начальном этапе структурной реформы [Pittman, 2004], но не был принят.

${ }_{18}$ При обязательном дотировании государством пригородных и междугородных пассажирских перевозок-как в европейской части, так и на востоке страны.
} 
Предлагаемое горизонтальное расщепление РЖД, в отличие от вертикального, проведенного в ходе Реформы, позволит использовать разные модели управления для европейской и азиатской частей железнодорожной инфраструктуры, максимально для них подходящие и учитывающие реальные условия их деятельности.

Чтобы в ходе расщепления не утратить эмерджентный эффект от единства железнодорожного технико-технологического комплекca, на наш взгляд, целесообразно воссоздать Министерство путей сообщения в его дореволюционном (до 2017 г.) варианте, когда под одной крышей было объединено государственное регулирование всех видов водного, сухопутного и железнодорожного транспорта. Очевидно, в новую структуру, которая заменит нынешний Минтранс, войдут лучшие профессиональные управленческие кадры РЖД и Минтранса. Такая «оптимизация» (выражаясь на бюрократическом сленге) не только сэкономит деньги налогоплательщиков, но и повысит качество управления транспортным комплексом страны и предотвратит беспокоящую железнодорожников потерю эмерджентного эффекта на более высоком уровне интеграции ${ }^{19}$.

В рамках стратегического аспекта, когда железнодорожный транспорт рассматривается как системообразующий элемент национальной безопасности России на ее восточных границах, рассмотрим три крупномасштабных железнодорожных проекта, находящихся на разных этапах своих жизненных циклов: Трансполярную магистраль ${ }^{20}$ (ТМ), Ленско-Камчатскую магистраль ${ }^{21}$ (ЛКМ) и железную дорогу Материк - Сахалин ${ }^{22}$ (MC).

\footnotetext{
${ }^{19}$ Из всех известных определений эмерджентности наиболее подходящим в нашем случае представляется слудующее: «Экономическая эмерджентность - это свойство экономических систем в процессе организации высокодуховных форм хозяйствования продуцировать (создавать) качества, которые отсутствовали на предыдущих ступенях ее развития. Данное свойство является следствием экономической квадратичности, цикличности и транспарентности» (см. URL: https://duheconomy.ucoz.org/publ/ehkonomicheskaja_ ehmerdzhentnost/1-1-0-36 (дата обращения: 28.06.2019).

${ }^{20}$ Трансполярная магистраль - недостроенная железная дорога Чум - Салехард Игарка, строившаяся в 1947-1953 годах структурами МВД СССР. Частично действует. Соединена с ж/д сетью страны через Печорскую железную дорогу. В более широком смысле Трансполярной магистралью называют проект железнодорожного пути от берегов Баренцева моря восточнее Архангельска до побережья Охотского моря и Чукотки.

21 Ленско-Камчатская магистраль - проект железной дороги, обеспечивающей круглогодичное сообщение населённых пунктов Камчатского края с Восточной Сибирью и югом Дальнего Востока. Протяжённость около 5 тыс. км.

22 Проект 580-километровой линии от ст. Селихин (Хабаровский край) до ст. Ныш (о-в Сахалин). Включает строительство мостового перехода через Татарский пролив.
} 
Эти проекты вместе с БАМом и Транссибом образуют систему широтных железнодорожных линий двойного назначения. Но если социально-экономические аспекты их деятельности давно и широко обсуждаются, то военно-стратегические до сих пор оставались как бы в тени, за исключением редких публикаций в специализирующихся на военной тематике научных изданиях, мало известных широкому кругу экспертов и отраслевых функционеров.

Сегодня ситуация кардинально изменилась. Конгресс США в 2017 г. утвердил законопроект H.R.3203 о новых санкциях в отношении России. Одновременно активизировались военные приготовления в Арктическом бассейне в рамках директивы «Новая арктическая стратегия США», подписанной президентом Б. Обамой еще в $2009 \Gamma^{23}$ В ее развитие главнокомандующий НАТО предложил считать Северный морской путь продолжением Гибралтарского пролива и установить над ним международную юрисдикцию ${ }^{24}$. Все это, вкупе с агрессивными заявлениями ряда американских генералов ${ }^{25,26}$ говорит не только об объявлении экономической войны нашей стране, но и о вполне реальном риске перехода к боестолкновениям в Арктике.

В Программе 2025, несмотря на ее стратегический характер, проблемы национальной безопасности России на восточных границах никак не затрагиваются. Это означает, что, по крайней мере, в течение ближайших семи лет прединвестиционные исследования по указанным выше проектам проводиться не будут. Следовательно, в случае обострения отношений в акваториях Северного Ледовитого и Тихого океанов, действия российского флота не смогут опереться на надежный береговой («железнодорожный») тыл. Нам такой подход представляется близоруким, демонстрирующим неспособность ответственных лиц государства и РЖД правильно оценить военно-стратегическую значимость железных дорог. Как показал печальный опыт русско-японской

\footnotetext{
${ }^{23}$ URL: http://pentagonus.ru/publ/doktrinalnye_vzgljady_ssha_i_kanady_na_osvoenie arktiki_2013/112-1-0-2424 (дата обращения: 28.06.2019).

${ }^{24}$ Американский генерал Кертис Скапаротти, выступая 8 марта 2019 г. в сенате США, предложил считать юрисдикцию СМП международной, а суверенитет России над СМП - незаконным. Подробнее см. URL: https://regnum.ru/news/polit/2389014.html (дата обращения: 30.06.2019).

${ }^{25}$ URL: https://realnoevremya.ru/news/129071-nachshtaba-vms-ssha-schitaet-neobhodimympreventivnyy-udar-po-rossii (дата обращения: 28.06.2019).

${ }^{26}$ URL: https://army-news.ru/2019/02/ssha-sobirayutsya-otxvatit-u-rossii-chast-arktiki/ (дата обращения: 28.06.2019).
} 
войны 1904-1905 гг, ограниченная пропускная способность недостроенного к началу военных действий Транссиба стала одной из причин поражения России не только на суше, но и на море.

Нелишне напомнить, как в первые же дни русско-японской войны противник напал на Камчатку и стал грабить и убивать ее жителей, а царское правительство не смогло оказать военную помощь своим гражданам из-за отсутствия устойчивой морской и сухопутной связи с полуостровом. Поэтому аборигены-камчадалы и ограниченный контингент казаков оборонялись от артиллерии захватчиков с помощью берданок ${ }^{27}$.

Одним словом, для того чтобы и здесь достойно пройти «последнюю милю», и гарантировать возможность отражения конкретных военных угроз со стороны США в Арктическом регионе, документы типа Программы 2025 должны не регламентировать «хождение по кругу», а содержать прорывные военно-стратегические установки, касающиеся национальной безопасности России.

\section{Литература/ References}

Быкадоров С.А., Кибалов Е.Б. К вопросу о совершенствовании модели управления железнодорожным транспортом России // ЭКО. 2018. № 3. C. 121-139.

Bykadorov, S.A., Kibalov, E.B. (2018). On the question of improving Russian railway management. ECO. No. 3. Pp. 121-139. (In Russ.).

Воронов Ю.П. «Последняя миля» как общеэкономическая проблема // Вопросы новой экономики. 2019. № 1 (49). С. 88-95.

Voronov, Yu.P. (2019). 'The last mile' as common economic problem. Questions of new economics. No. 1 (49). Pp. 88-95. (In Russ.).

Иванов Д. А. Управление цепями поставок. СПб.: Изд-во Политехнического ун-та, 2009. $660 \mathrm{c}$.

Ivanov, D.A. (2009). Managing supply chain. St-Petersburg; Published by Politechnical university. 660 p. (In Russ.).

Кибалов Е.Б., Кин А.А., Быкадоров С.А. О развитии структурной реформы железнодорожного транспорта России // Регион: экономика и социология. 2015. № 4 (88). C. 162-178.

Kibalov, E.B., Kin, A.A., Bykadorov, S.A. (2015). On development of the structural reform of Russian railway transport. Region: economics and sociology. No. 4 (88). Pp.162-178. (In Russ.).

Кибалов Е.Б., Кин А.А. Реформа железнодорожного транспорта: критический анализ и проблема оценки эффективности / Под ред. чл.-корр. РАН В. А. Крюкова. Новосибирск: Монография. Изд-во ИЭОПП СО РАН, 2017. 160 с.

${ }^{27}$ URL: http://www.antikvarovnet.ru/viewtopic.php?f=114\&t=331 (дата обращения: 28.06.2019). 
Kibalov, E.B., Kin, A.A. (2017). The railway reform: critical analysis and efficiency evaluation problem. Edited by V.A. Kryukov, corresponding member of RAS. Novosibirsk. Published by IEIE. 160 p. (In Russ.).

Лебедев А. Вперед к МПС? // РЖД-Партнёр. 2019. № 7. С. 34-35.

Lebedev, A. (2019). Forward to the railway ministry? RZhD-Partner. No. 7. Pp. 34-35. (In Russ.).

Полтерович В.M. Институциональные ловушки и экономические реформы // Экономика и математические методы. 1999. Т. 35. Вып. 2.

Polterovich, V.M. (1999). Institutional traps and economic reforms. Economics and mathematical methods. Vol. 35. Iss. 2. (In Russ.).

Талеб Н. Н. Черный лебедь. Под знаком неопредсказуемости: пер. с англ. 2-е изд., доп. М.: КоЛибри; Азбука-Аттикус, 2015. 736 с.

Taleb, N.N. (2015). Black swan. The impact of highly improbable. Moscow. CoLibri. Azbuka-Atticus, 736 p. (In Russ.).

Pittman, R. (2004). Reform of Russian Railways and the problem of nondiscriminatory access to infrastructure. Annals of Public and Cooperative Economics", June. Vol. 75. Iss. 2. Pp. 167-192.

Статья поступила 17.09.2019.

Для цитирования: Быкадоров С.А., Кибалов Е.Б. Реформа железнодорожного транспорта: «последняя миля»// ЭКО. 2019. № 11. С. 156-171. DOI: 10.30680/ECO0131-7652-2019-11-156-171.

For citation: Bykadorov, S.A., Kibalov, E.B. (2019). The Reform of Railway Transport in Russia: "the Last Mile". ECO. No. 11. Pp. 156-171. (In Russ.). DOI: 10.30680/ECO0131-7652-2019-11-156-171.

\section{Summary}

Bykadorov, S. A., Doct. Sci. (Econ.), Siberian State Transport University (STU), Kibalov, E. B., Doct. Sci. (Econ.), Institute of Economics and Industrial Engineering, SB RAS, Novosibirsk

\section{The Reform of Railway Transport in Russia: "the Last Mile"}

Abstract. The paper represents a critical analysis of the long-term development program of JSC "Russian Railways" until 2025, approved by the Russian Government on March 19, 2019. The authors review possible options for improving the management model of "Russian Railways" under sanctions and military threats from the collective West. The paper assesses comparative social efficiency of dual-purpose railway projects (socio-economic and military-strategic) in the East of the country (Transpolar, Lensko-Kamchatka highways and the mainland-Sakhalin railway).

Keywords: long-term program; scenarios; sanctions; uncertainty factor; dualuse railway projects; reform; Russian Railways; European Russia; Asian Russia; North sea route 